\section{Dyslipidaemia and microvascular disease in the retina}

H Leung', JJ Wang', E Rochtchina', TY Wong', R Klein ${ }^{2}$ and P Mitchell ${ }^{1}$

\section{Introduction}

Elevated serum cholesterol is a major risk factor for large vessel atherosclerosis, ${ }^{1,2}$ and lowering cholesterol has been demonstrated to reduce clinical atherosclerotic diseases such as coronary heart disease. ${ }^{3,4}$ However, the processes involved in atherosclerosis (arteriosclerosis affecting arteries) may be somewhat different to those in arteriolosclerosis (arteriosclerosis affecting smaller arteriolar branches) $)^{5,6}$ and therefore the relationship of dyslipidaemia to arteriolosclerosis is less clear. There is some evidence that hypercholesterolaemia may also cause both functional $1^{5,7-10}$ and structural changes ${ }^{11,12}$ in the peripheral microvasculature. However, there are fewer clinical data available, largely because the human microcirculation is difficult to evaluate outside specialised settings.

The retinal microcirculation offers an opportunity to directly study the effects of dyslipidaemia on small vessel disease. Several recent population-based studies have not demonstrated a consistent association between retinal microvascular signs and serum lipid levels. In the Atherosclerosis Risk in Communities (ARIC) study ${ }^{13}(n=9300$, aged 50-71 years), after adjusting for age, sex, race, mean arterial blood pressure (MABP), and antihypertensive medication use, generalised arteriolar narrowing was related to higher serum triglycerides $(P=0.012)$ and lower highdensity lipoprotein (HDL) cholesterol $(P=0.08)$, but not related to total cholesterol or lowdensity lipoprotein (LDL) cholesterol. Also, focal arteriolar narrowing was related to lower serum cholesterol, while arteriovenous (AV) nicking was related to lower HDL cholesterol levels. In contrast, the Cardiovascular Health Study (CHS, $n=2405$, aged 69-97 years) found no association between retinal microvascular signs and any measures of serum lipid, after multivariate adjustment. ${ }^{14}$ In the Hoorn study ( $n=626$, age 50-74 years), ${ }^{15}$ after adjusting for age, sex, and glucose metabolism category, retinopathy was associated with higher total
${ }^{1}$ Department of Ophthalmology and the Westmead Millennium Institutes, Centre for Vision Research, The University of Sydney, Australia

${ }^{2}$ Department of Ophthalmology \& Visual Science, University of Wisconsin-Madison WI, USA

Correspondence:

Dr JJ Wang

Department of Ophthalmology Centre for Vision Research

Westmead Hospital University of Sydney Hawkesbury Rd, Westmead N.S.W. 2145, Australia Tel: + 61298455006 Fax: + 61298458345 E-mail: jiejin_wang@ wmi.usyd.edu.au

Received: 14 February 2004 Accepted: 15 June 2004 Published online:

3 September 2004

Presented at the 2003 Australasian Ophthalmic and Visual Science Meeting, Melbourne, November 2003

Proprietary Interest: None 
cholesterol and triglyceride levels, but not associated with HDL or LDL cholesterol levels.

To determine the influence of elevated serum lipids on the retinal microvasculature, we aimed to examine the relations between serum lipid levels and retinal microvascular signs in a well-defined community-based older Australian population, while controlling for blood pressure (BP) and other confounders.

\section{Methods}

The Blue Mountains Eye Study is a population-based cohort study of vision, common eye diseases, and other health outcomes in a suburban population aged 49 years or older. This study was conducted according to the recommendations of the Declaration of Helsinki, and was approved by the University of Sydney and the Western Sydney Area Human Ethics Committees. Written, informed consent was obtained from all participants. Baseline examinations were conducted during 19921994, and the 3654 participants represented $82.4 \%$ of eligible potential participants living in two postcode areas in the Blue Mountains, Australia.

At the baseline examinations, dilated, 30-degree stereoscopic retinal photographs of the macula, optic disc, and other retinal fields of both eyes were taken, using a Zeiss FF3 fundus camera (Carl Zeiss, Oberkochen, Germany). Methods of image digitisation and grading protocols have been described in detail. ${ }^{16}$ Briefly, a trained grader selected a segment of each vessel completely passing a zone between half and one disc diameter away from the optic disc margin. Each vessel was identified as an arteriole or a venule using the original colour photograph as reference;

'RetinalAnalysis' software performed the measurements. Branches of all arterioles $\geq 85 \mu \mathrm{m}$ were also measured, provided that the two branches could be measured accurately. Vessels measuring less than $25 \mu \mathrm{m}$ were excluded. Eyes were considered ungradeable if one vessel $\geq 45 \mu \mathrm{m}$ could not be measured accurately.

The Parr-Hubbard formula ${ }^{16}$ was used to summarise measurements obtained from each eye as indices of average arteriolar (central retinal arteriolar equivalent, CRAE) and venular (central retinal venular equivalent, CRVE) diameter. CRAE was divided by CRVE to obtain arteriole-to-venular ratio (AVR). As previously reported, the reliability of this measurement was high, with quadratic weighted kappa values between 0.75 and 0.9 for intergrader reliability and between 0.8 and 0.93 for intragrader reliability. ${ }^{17}$ Only right-eye measurements were used, as good correlation was found between right- and left-eye measurements. ${ }^{18}$ Generalised retinal arteriolar narrowing was defined as CRAE or AVR within the lowest quintile in the population.

Focal arteriolar narrowing, AV nicking, and presence of retinopathy lesions (microaneurysms, haemorrhages, hard/soft exudates) were graded from $35 \mathrm{~mm}$ slides of both eyes by one grader, using a light box (Kelvin rating approximately $6200^{\circ}$ ) and a Donaldson stereo-viewer with $\times 5$ magnification. Only arterioles located at least one half-disc diameter away from the optic disc margin were assessed for focal arteriolar narrowing and $\mathrm{AV}$ nicking. Standard photographs were selected by a retinal specialist (PM) from the standard photographic set developed for the Modified Airlie House Classification of Diabetic Retinopathy ${ }^{19}$ and the Wisconsin Age-related Maculopathy Grading System. ${ }^{20}$ Focal arteriolar narrowing was graded as absent/ questionable (none/ less severe than the standard photograph) or present (equal to or more severe than the standard). AV nicking was defined as a decrease in venular width on both sides of the venule where crossed by an arteriole and was graded as absent/questionable, mild (less than the standard), or severe (equal to or greater than the standard). The intragrader reliability for detecting focal arteriolar narrowing and AV nicking were (kappa statistic) 0.80 and 0.87 , respectively. Grading of nondiabetic retinopathy lesions has been reported previously. ${ }^{21}$ Lesions in the worse eye were chosen to classify the person.

$\mathrm{BP}$ was measured once using a mercury sphygmomanometer, after the participants had been comfortably seated for at least $5 \mathrm{~min}$. MABP was defined as $0.33 \times$ systolic $\mathrm{BP}+0.67 \times$ diastolic BP. Hypertension was defined in persons who were using antihypertensive medications or were found to have systolic $\mathrm{BP} \geqslant 160 \mathrm{mmHg}$ or diastolic $\mathrm{BP} \geqslant 95 \mathrm{mmHg}$ at examinations. In all, 3224 (89\%) participants returned for fasting blood tests, which included total cholesterol, triglycerides, and HDL cholesterol. These tests were performed on a 747 Biochemistry Analyzer (Hitachi, Tokyo, Japan). LDL cholesterol was calculated by the Friedewald formula used in the ARIC study: LDL cholesterol $=$ total cholesterol $-\mathrm{HDL}$ cholesterol-(triglycerides/5). ${ }^{13}$ Body weight and height were measured and body-mass index (BMI) was calculated as weight $(\mathrm{kg}) /$ height $(\mathrm{m})^{2}$. Diabetes was diagnosed by either medical history or fasting blood glucose $\geqslant 7.0 \mathrm{mmol} / \mathrm{l}$.

\section{Statistical methods}

Statistical Analysis System (SAS version 8.0, SAS Institute, Cary, NC, USA) was used for statistical analysis. Adjusted means and their standard errors (SE) 
were calculated using general linear models. Logistic regression models were used to determine the odds

Table 1 Comparison of persons included and excluded in the current study

\begin{tabular}{lrrc}
\hline & $\begin{array}{c}\text { Included } \\
(\mathrm{n}=2918)\end{array}$ & $\begin{array}{r}\text { Excluded } \\
(\mathrm{n}=306)\end{array}$ & $\begin{array}{c}\mathrm{P} \\
\text { values* }\end{array}$ \\
\hline Men (\%) & 42.9 & 43.5 & 0.9 \\
Mean age (years) & 65.4 & 71.3 & $<0.0001$ \\
Mean systolic BP (mmHg) & 146.1 & 149.6 & 0.008 \\
Mean diastolic BP (mmHg) & 83.4 & 83.3 & 0.8 \\
Mean arterial BP (mmHg) & 104.1 & 105.2 & 0.2 \\
Mean total cholesterol (mmol/1) & 6.0 & 6.0 & 1 \\
Mean LDL cholesterol (mmol/1) & 4.2 & 4.2 & 0.8 \\
Mean HDL cholesterol (mmol/1) & 1.4 & 1.5 & 0.1 \\
Mean triglyceride (mmol/1) & 1.8 & 1.6 & 0.04 \\
Hypertension (\%) & 45.5 & 50.5 & 0.1 \\
Diabetes (\%) & 8.0 & 8.2 & 0.9 \\
Cigarette smoking, ever (\%) & 50.6 & 53.6 & 0.4 \\
\hline
\end{tabular}

${ }^{*}$ Comparing means or proportions between included and excluded $\mathrm{HDL}=$ high-density lipoprotein; $\mathrm{LDL}=$ low-density lipoprotein. ratios (OR) and 95\% confidence intervals (CI) for retinal microvascular signs, after adjusting for age, sex, BMI, smoking, and MABP.

\section{Results}

Of the 3224 participants who returned for fasting blood tests, 306 had ungradeable photographs or missing data, leaving 2918 included in the present analyses. Of those included, 1329 had hypertension and 234 had diabetes. Comparisons between persons included and excluded in the analyses are shown in Table 1 . In general, those excluded were older and had higher mean systolic BP and slightly lower mean triglyceride levels.

Table 2 shows mean retinal vessel parameters $( \pm S E)$ by quintile of serum lipid levels, after controlling for age, sex, BMI, smoking, and MABP. Increasing quintiles of HDL cholesterol were associated with narrower retinal arterioles $\left(P_{\text {trend }}=0.002\right)$ and venules $\left(P_{\text {trend }}=0.03\right)$, while serum triglyceride had a U-shaped relationship with mean venular diameter $\left(P_{\text {trend }}=0.003\right)$. Neither total nor

Table 2 Mean retinal vessel parameters $( \pm$ SE) by quintile of serum lipid levels, after adjusting for age, sex, BMI, mean arterial BP, and smoking

\begin{tabular}{|c|c|c|c|}
\hline Serum lipids & Mean arteriolar diameters $(\mu \mathrm{m})$ & Mean venular diameters $(\mu m)$ & Mean arteriole-to-venule ratio \\
\hline \multicolumn{4}{|l|}{ Total cholesterol } \\
\hline Lowest quintile & $193.7 \pm 0.8$ & $225.3 \pm 0.8$ & $0.862 \pm 0.003$ \\
\hline Second quintile & $192.4 \pm 0.8$ & $224.2 \pm 0.8$ & $0.860 \pm 0.003$ \\
\hline Third quintile & $193.3 \pm 0.8$ & $225.1 \pm 0.8$ & $0.861 \pm 0.003$ \\
\hline Fourth quintile & $192.5 \pm 0.8$ & $223.9 \pm 0.8$ & $0.862 \pm 0.003$ \\
\hline Highest quintile & $193.2 \pm 0.8$ & $226.4 \pm 0.8$ & $0.856 \pm 0.003$ \\
\hline$P$ for trend & $0 . \overline{7}$ & $0 . \overline{2}$ & 0.7 \\
\hline \multicolumn{4}{|l|}{ HDL cholesterol } \\
\hline Lowest quintile & $196.0 \pm 0.9$ & $227.1 \pm 0.9$ & $0.865 \pm 0.004$ \\
\hline Second quintile & $193.5 \pm 0.8$ & $225.5 \pm 0.8$ & $0.860 \pm 0.003$ \\
\hline Third quintile & $192.6 \pm 0.8$ & $223.6 \pm 0.8$ & $0.863 \pm 0.003$ \\
\hline Fourth quintile & $192.6 \pm 0.8$ & $225.2 \pm 0.8$ & $0.858 \pm 0.003$ \\
\hline Highest quintile & $190.8 \pm 0.8$ & $223.6 \pm 0.9$ & $0.856 \pm 0.003$ \\
\hline$P$ for trend & 0.002 & 0.03 & 0.4 \\
\hline \multicolumn{4}{|l|}{ LDL cholesterol } \\
\hline Lowest quintile & $191.7 \pm 0.8$ & $224.1 \pm 0.8$ & $0.858 \pm 0.003$ \\
\hline Second quintile & $193.7 \pm 0.8$ & $225.2 \pm 0.8$ & $0.862 \pm 0.003$ \\
\hline Third quintile & $193.8 \pm 0.8$ & $225.0 \pm 0.8$ & $0.864 \pm 0.003$ \\
\hline Fourth quintile & $193.3 \pm 0.8$ & $224.2 \pm 0.8$ & $0.864 \pm 0.003$ \\
\hline Highest quintile & $192.9 \pm 0.8$ & $226.3 \pm 0.8$ & $0.855 \pm 0.003$ \\
\hline$P$ for trend & $0 . \overline{4}$ & $0 . \overline{3}$ & 0.2 \\
\hline \multicolumn{4}{|l|}{ Triglycerides } \\
\hline Lowest quintile & $193.8 \pm 0.9$ & $226.6 \pm 0.9$ & $0.858 \pm 0.003$ \\
\hline Second quintile & $192.6 \pm 0.7$ & $222.8 \pm 0.7$ & $0.866 \pm 0.003$ \\
\hline Third quintile & $192.7 \pm 0.9$ & $225.5 \pm 0.9$ & $0.857 \pm 0.004$ \\
\hline Fourth quintile & $192.7 \pm 0.8$ & $224.3 \pm 0.8$ & $0.861 \pm 0.003$ \\
\hline Highest quintile & $193.6 \pm 0.8$ & $226.5 \pm 0.8$ & $0.857 \pm 0.003$ \\
\hline$P$ for trend & $0 . \overline{8}$ & 0.003 & $\overline{0.1}$ \\
\hline
\end{tabular}

$\mathrm{HDL}=$ high-density lipoprotein; $\mathrm{LDL}=$ low-density lipoprotein. 
Table 3 Associations between serum lipid levels and generalised retinal arteriolar narrowing, after adjusting for age, sex, BMI, smoking, and mean arterial BP

\begin{tabular}{|c|c|c|c|c|}
\hline \multirow[t]{2}{*}{ Serum lipids } & \multicolumn{2}{|c|}{ Narrowest quintile of $C R A E$} & \multicolumn{2}{|c|}{ Narrowest quintile of $A V R$} \\
\hline & $\%$ Affected & OR $(95 \% C I)$ & $\%$ Affected & OR $(95 \% C I)$ \\
\hline \multicolumn{5}{|l|}{ Total cholesterol } \\
\hline Lowest quintile & 20.4 & 1.0 & 20.7 & 1.0 \\
\hline Second quintile & 20.4 & $1.1(0.8,1.4)$ & 21.1 & $1.1(0.8,1.5)$ \\
\hline Third quintile & 20.0 & $1.0(0.8,1.4)$ & 21.2 & $1.1(0.9,1.5)$ \\
\hline Fourth quintile & 20.6 & $1.2(0.9,1.6)$ & 16.8 & $0.9(0.7,1.2)$ \\
\hline Highest quintile & 19.7 & $1.0(0.7,1.3)$ & 21.2 & $1.2(0.9,1.6)$ \\
\hline$P$ for trend & & 0.9 & & 0.6 \\
\hline \multicolumn{5}{|l|}{ HDL cholesterol } \\
\hline Lowest quintile & 17.8 & 1.0 & 20.5 & 1.0 \\
\hline Second quintile & 19.0 & $1.2(0.9,1.6)$ & 22.8 & $1.3(0.9,1.7)$ \\
\hline Third quintile & 21.7 & $1.4(1.0,1.9)$ & 19.3 & $1.1(0.8,1.5)$ \\
\hline Fourth quintile & 19.6 & $1.3(0.9,1.7)$ & 19.0 & $1.2(0.9,1.7)$ \\
\hline Highest quintile & 22.7 & $1.6(1.1,2.2)$ & 19.7 & $1.4(1.0,1.9)$ \\
\hline$P$ for trend & & 0.009 & & 0.1 \\
\hline \multicolumn{5}{|l|}{ LDL cholesterol } \\
\hline Lowest quintile & 21.6 & 1.0 & 21.1 & 1.0 \\
\hline Second quintile & 20.5 & $1.0(0.7-1.3)$ & 19.3 & $0.9(0.7-1.2)$ \\
\hline Third quintile & 18.9 & $0.8(0.6-1.1)$ & 22.2 & $1.1(0.8-1.4)$ \\
\hline Fourth quintile & 20.9 & $1.0(0.7-1.3)$ & 17.6 & $0.8(0.6-1.1)$ \\
\hline Highest quintile & 19.2 & $0.9(0.6-1.2)$ & 20.9 & $1.0(0.8-1.4)$ \\
\hline$P$ for trend & & 0.4 & & 1.0 \\
\hline \multicolumn{5}{|l|}{ Triglycerides } \\
\hline Lowest quintile & 19.3 & 1.0 & 20.0 & 1.0 \\
\hline Second quintile & 22.2 & $1.3(0.9,1.7)$ & 18.2 & $0.9(0.7,1.2)$ \\
\hline Third quintile & 19.7 & $1.0(0.7,1.5)$ & 21.1 & $1.0(0.8,1.4)$ \\
\hline Fourth quintile & 19.5 & $1.1(0.8,1.5)$ & 18.9 & $0.9(0.7,1.2)$ \\
\hline Highest quintile & 19.8 & $1.1(0.8,1.6)$ & 23.9 & $1.1(0.8,1.6)$ \\
\hline$P$ for trend & & 0.8 & & 0.2 \\
\hline
\end{tabular}

$\mathrm{CRAE}=$ central retinal arteriolar equivalent; $\mathrm{AVR}=$ arteriole-to-venule ratio; $\mathrm{CI}=$ confidence interval; $\mathrm{HDL}=$ high-density lipoprotein; $\mathrm{LDL}=$ low-density lipoprotein.

LDL cholesterol was related to any retinal vessel parameters.

Table 3 shows the associations between serum lipid levels and generalised retinal arteriolar narrowing. Compared to persons with the lowest quintile of HDL cholesterol, those with the highest quintile of HDL cholesterol were $60 \%$ more likely to have generalised arteriolar narrowing, defined by CRAE (OR 1.6, 95\% CI 1.1-2.2). Generalised arteriolar narrowing, whether defined by CRAE or AVR, was not associated with serum total cholesterol, LDL cholesterol, or triglyceride levels. Further stratified analyses showed that the inverse association between HDL cholesterol and CRAE-defined generalised narrowing remained significant in men younger than 65 years, persons with hypertension, persons without diabetes, persons not receiving cholesterol lowering medications, and persons giving a history of cigarette smoking (data not shown). HDL cholesterol was not significantly associated with AVRdefined generalised narrowing in the analyses that included all subjects. Further stratified analyses, however, showed that compared with the lowest HDL quintile, the highest HDL quintile was significantly associated with AVR-defined narrowing in men younger than 65 years (OR 2.5, 95\% CI 1.2-5.4, $P_{\text {trend }}=0.03$ ), in persons with diabetes (OR 6.3, 95\% CI 1.6-24.0, $\left.P_{\text {trend }}=0.007\right)$ and in ever smokers (OR 2.0, 95\% CI 1.3-3.0, $P_{\text {trend }}=0.002$ ).

Table 4 shows that after adjusting for age, sex, BMI, smoking, and MABP, focal arteriolar narrowing, AV nicking and retinopathy lesions were not related to any measures of serum lipid. Further stratified analyses showed that AV nicking was significantly associated with higher triglyceride levels in women older than 65 years $\left(P_{\text {trend }}=0.02\right)$, whereas focal arteriolar narrowing was significantly related to total cholesterol $\left(P_{\text {trend }}=0.03\right)$ and 
Table 4 Associations between serum lipids and focal arteriolar narrowing, AV nicking and retinopathy lesions, after adjusting for age, sex, BMI, smoking and mean arterial BP

\begin{tabular}{|c|c|c|c|c|c|c|}
\hline \multirow[t]{2}{*}{ Serum lipids } & \multicolumn{2}{|c|}{ Focal arteriolar narrowing } & \multicolumn{2}{|c|}{ AV Nicking } & \multicolumn{2}{|c|}{ Retinopathy lesions } \\
\hline & $\%$ affected & OR $(95 \% C I)$ & $\%$ affected & OR $(95 \% C I)$ & $\%$ affected & OR $(95 \% \mathrm{CI})$ \\
\hline \multicolumn{7}{|l|}{ Total cholesterol } \\
\hline Lowest quintile & 8.1 & 1.0 & 8.2 & 1.0 & 12.2 & 1.0 \\
\hline Second quintile & 7.6 & $1.0(0.7-1.6)$ & 8.5 & $1.0(0.7-1.5)$ & 12.2 & $1.0(0.7-1.4)$ \\
\hline Third quintile & 8.9 & $1.3(0.8-2.0)$ & 8.7 & $1.1(0.7-1.6)$ & 11.8 & $1.0(0.7-1.4)$ \\
\hline Fourth quintile & 6.5 & $0.9(0.5-1.4)$ & 8.5 & $1.0(0.7-1.6)$ & 10.3 & $0.8(0.5-1.2)$ \\
\hline Highest quintile & 8.2 & $0.9(0.6-1.4)$ & 10.7 & $1.2(0.8-1.8)$ & 10.4 & $0.8(0.5-1.1)$ \\
\hline$P$ for trend & & 0.5 & & 0.2 & & 0.1 \\
\hline \multicolumn{7}{|l|}{ HDL cholesterol } \\
\hline Lowest quintile & 7.6 & 1.0 & 9.6 & 1.0 & 12.9 & 1.0 \\
\hline Second quintile & 7.8 & $1.0(0.6-1.6)$ & 9.2 & $1.0(0.6-1.4)$ & 10.8 & $0.8(0.5-1.1)$ \\
\hline Third quintile & 8.3 & $0.9(0.6-1.5)$ & 9.4 & $1.0(0.7-1.5)$ & 12.5 & $0.9(0.6-1.4)$ \\
\hline Fourth quintile & 5.8 & $0.6(0.3-0.9)$ & 8.4 & $0.9(0.6-1.4)$ & 10.8 & $0.8(0.6-1.2)$ \\
\hline Highest quintile & 10.0 & $1.2(0.7-1.9)$ & 8.2 & $0.9(0.6-1.4)$ & 10.1 & $0.7(0.5-1.1)$ \\
\hline$P$ for trend & & 0.7 & & 0.6 & & 0.2 \\
\hline \multicolumn{7}{|l|}{ LDL cholesterol } \\
\hline Lowest quintile & 8.3 & 1.0 & 8.9 & 1.0 & 10.3 & 1.0 \\
\hline Second quintile & 8.1 & $1.0(0.6-1.5)$ & 8.0 & $0.8(0.6-1.3)$ & 13.1 & $1.3(0.9-1.9)$ \\
\hline Third quintile & 8.0 & $1.1(0.7-1.6)$ & 8.7 & $0.9(0.6-1.4)$ & 10.4 & $1.0(0.7-1.4)$ \\
\hline Fourth quintile & 7.5 & $0.9(0.6-1.4)$ & 8.3 & $0.8(0.6-1.3)$ & 13.1 & $1.2(0.8-1.8)$ \\
\hline Highest quintile & 7.4 & $0.8(0.5-1.3)$ & 10.7 & $1.1(0.8-1.6)$ & 9.8 & $0.9(0.6-1.3)$ \\
\hline$P$ for trend & & 0.4 & & 0.5 & & 0.4 \\
\hline \multicolumn{7}{|l|}{ Triglycerides } \\
\hline Lowest quintile & 7.6 & 1.0 & 7.3 & 1.0 & 9.6 & 1.0 \\
\hline Second quintile & 7.6 & $0.9(0.6-1.4)$ & 8.7 & $1.1(0.7-1.7)$ & 11.1 & $1.1(0.8-1.6)$ \\
\hline Third quintile & 9.9 & $1.2(0.8-2.0)$ & 8.1 & $1.0(0.6-1.5)$ & 12.3 & $1.2(0.8-1.8)$ \\
\hline Fourth quintile & 8.0 & $1.0(0.7-1.6)$ & 9.5 & $1.1(0.8-1.7)$ & 12.8 & $1.3(0.9-1.9)$ \\
\hline Highest quintile & 6.6 & $0.9(0.5-1.5)$ & 10.7 & $1.3(0.8-1.9)$ & 11.2 & $1.2(0.8-1.8)$ \\
\hline$P$ for trend & & 0.6 & & 0.2 & & 0.5 \\
\hline
\end{tabular}

$\mathrm{CI}=$ confidence interval; $\mathrm{HDL}=$ high-density lipoprotein; $\mathrm{LDL}=$ low-density lipoprotein.

LDL cholesterol $\left(P_{\text {trend }}=0.03\right)$ in persons with diabetes. All other associations did not reach statistical significance.

After including BP-lipid interaction terms in the models, triglyceride level was significantly associated with generalised narrowing but not with focal narrowing. Conversely, cholesterol or LDL cholesterol was significantly associated with focal narrowing but not with generalised narrowing.

\section{Discussion}

The aim of this study was to examine the relation between dyslipidaemia and retinal microvascular disease. We did not find a statistically significant association between retinal microvascular signs and serum triglyceride, LDL cholesterol, or total cholesterol levels. Using a computer-assisted method to quantify vessel diameter from digitised retinal images, we found a cross-sectional association between narrowed retinal vessel diameters and higher HDL cholesterol levels, after adjusting for BP and other covariables. We also checked interactions between BP and blood lipids in the multivariable models, and observed inconsistent patterns of interactions in the models for generalised and focal arteriolar narrowing. Thus, we cannot exclude the possibility of chance findings in these analyses.

Dyslipidaemia is one of the strongest predictors of large vessel atherosclerotic disease. Clinical trials have conclusively shown that lowering serum cholesterol reduces the risk of coronary heart disease and mortality. ${ }^{3,4}$ However, only a few clinical studies have examined the association between dyslipidaemia and small vessel arteriolosclerosis.

Recent studies have shown that retinal microvascular changes are markers of subclinical systemic vascular disease, and are strongly associated with hypertension ${ }^{22,23}$ and predict stroke, ${ }^{24}$ coronary heart 
disease ${ }^{25}$ and mortality, ${ }^{26}$ independent of BP and other traditional risk factors. However, animal and clinical studies have not demonstrated a consistent pattern of association between retinal microvascular changes and dyslipidaemia. Using a computer-assisted technique to measure vessel diameter from digitised retinal images of rats, Tomida et al ${ }^{27}$ demonstrated no significant differences in retinal vessel diameters between hypercholesterolaemic rats and controls. In contrast, using a calibre micrometer to measure vessel diameter from magnified retinal photographs, another study ${ }^{28}$ documented significant widening of retinal arteries and veins $(P<0.0001$ for both) in rats with inherited hypercholesterolaemia compared with controls. Clinical studies examining whether retinal microvascular disease is related to elevated serum cholesterol have been limited by small sample sizes of highly selected subjects, ${ }^{29-32}$ subjective assessment of arteriolar narrowing from fundus photographs ${ }^{31}$ and lack of adjustment for blood pressure, ${ }^{29,31}$ a strong factor associated with retinal arteriolar abnormalities,,$^{22,23,33}$ in the analyses. In one study, Orlin $e t a l^{31}$ found no increased prevalence of retinal arteriolar changes, as assessed from fundus photography, in 26 patients with severe hyperlipidaemia compared with 22 age-matched controls. In larger population-based studies, such as the ARIC study ${ }^{13}$ and the $\mathrm{CHS},{ }^{14}$ total cholesterol levels were not related to generalised arteriolar narrowing or AV nicking. Our findings add further support to the lack of relationship between serum cholesterol and retinal microvascular changes.

Like total cholesterol, low serum HDL cholesterol is a well-established cardiovascular risk factor. ${ }^{2,34,35}$ In the current study, we found a significant association between lower HDL cholesterol levels and wider retinal arteriolar diameters $(P=0.002)$. This finding is somewhat unexpected, and contrasts with data reported by the ARIC study. ${ }^{13}$ However, our data are consistent with findings from two previous studies that brachial arterial diameters were wider in persons with lower HDL cholesterol than in those with higher HDL cholesterol levels. ${ }^{36,37}$ Explanation of such findings is not readily available. Atherosclerosis is traditionally described as a gradual ingrowth of plaques within the vessel lumen, leading to narrowed vessel diameter. Recent data suggest that atherosclerosis can also result in remodelling of the arterial wall and may lead to either arterial expansion or shrinkage. ${ }^{38}$ Thus, direction of change in arterial and arteriolar diameter could be a manifestation of atherosclerosis related to low-HDL cholesterol levels.

The role of hypertriglyceridaemia as an independent risk factor for atherosclerosis remains unclear. ${ }^{39}$ Several studies have examined the effects of hypertriglyceridaemia on vasomotor function of peripheral vessels, with inconsistent results. ${ }^{39-41}$ Triglyceride levels were related to generalised arteriolar narrowing in the ARIC study $(P=0.012)^{13}$ and retinopathy in the Hoorn Study, ${ }_{15}^{15}$ but not related to any retinal microvascular signs neither in the $\mathrm{CHS}^{14}$ nor in our study. However, we found a U-shaped relationship between triglyceride levels and retinal venular diameter in the current study. We also found a significant association between triglyceride levels and generalised arteriolar narrowing when the model includes an interaction term of BP and triglyceride level. This finding needs further confirmation, as it was not hypothesised $a$ priori, and we could not compare such finding with the ARIC study ${ }^{13}$ and the $\mathrm{CHS},{ }^{14}$ as no data in this regard have been reported by these two studies.

One explanation for the contrasting findings between our current study and the ARIC study is the older age of participants in the current study (mean age 65.5 and around 60 years, respectively). There is some evidence that the association of dyslipidaemia and atherosclerotic diseases are weaker in older compared to younger people. ${ }^{42-44}$ It is possible that the association of dyslipidaemia and small vessel disease differs by age as well. In support of this, we showed that generalised arteriolar narrowing was significantly associated with higher HDL levels in younger ( $<65$ years) but not in older ( $\geqslant 65$ years) men.

A limitation of this study was the use of fasting serum samples to measure triglyceride levels. Because triglyceride levels are known to vary after meals, ${ }^{45}$ fasting triglyceride levels might not reflect the levels at the time when the retinal photographs were taken. Another limitation was the use of Freidwald equation to calculate LDL cholesterol levels. Such calculation was suggested to be inaccurate when triglyceride levels are higher than $5 \mathrm{mmol} / \mathrm{l}^{39}$ resulting in a possible systematic error among hypertriglyceridaemic subjects.

In conclusion, our population-based data find no association between retinal microvascular signs and serum total or LDL cholesterol, strong risk factors for atherosclerosis. In our previous analysis, we have demonstrated strong associations of retinal microvascular signs with hypertension. ${ }^{22}$ Thus, our findings here are in keeping with the concept that retinal microvascular signs are hypertensive processes largely distinct from large vessel atherosclerosis.

\section{Acknowledgements}

Supported by the Australian National Health and Medical Research Council, Canberra, Australia (Grant 153948 to Mitchell \& co-workers) and the National Eye Institute, Bethesda, USA (Grants NIH EY06594 and HL 59259 to Klein and coworkers). 


\section{References}

1 Heiss G, Sharrett AR, Barnes R, Chambless LE, Szklo M, Alzola C. Carotid atherosclerosis measured by B-mode ultrasound in populations: associations with cardiovascular risk factors in the ARIC study. Am J Epidemiol 1991; 134: 250-256.

2 Wilt TJ, Rubins HB, Robins SJ, Riley WA, Collins D, Elam M et al. Carotid atherosclerosis in men with low levels of HDL cholesterol. Stroke 1997; 28: 1919-1925.

3 Buchwald H, Varco RL, Boen JR, Williams SE, Hansen BJ, Campos CT et al. Effective lipid modification by partial ileal bypass reduced long-term coronary heart disease mortality and morbidity: five-year posttrial follow-up report from the POSCH. Program on the Surgical Control of the Hyperlipidemias. Arch Int Med 1998; 158: 1253-1261.

4 Prevention of cardiovascular events and death with pravastatin in patients with coronary heart disease and a broad range of initial cholesterol levels. The Long-Term Intervention with Pravastatin in Ischaemic Disease (LIPID) Study Group. N Engl J Med 1998; 339: 1349-1357.

5 Scalia R, Appel III JZ, Lefer AM. Leukocyte-endothelium interaction during the early stages of hypercholesterolemia in the rabbit: role of P-selectin, ICAM-1, and VCAM-1. Arterioscler Thromb Vasc Biol 1998; 18: 1093-1100.

6 Stokes KY, Cooper D, Tailor A, Granger DN. Hypercholesterolemia promotes inflammation and microvascular dysfunction: role of nitric oxide and superoxide. Free Radic Biol Med 2002; 33: 1026-1036.

7 Binggeli C, Spieker LE, Corti R, Sudano I, Stojanovic V, Hayoz D et al. Statins enhance postischemic hyperemia in the skin circulation of hypercholesterolemic patients: a monitoring test of endothelial dysfunction for clinical practice? J Am Coll Cardiol 2003; 42: 71-77.

8 Stulc T, Kasalova Z, Prazny M, Vrablik M, Skrha J, Ceska R. Microvascular reactivity in patients with hypercholesterolemia: effect of lipid lowering treatment. Physiol Res 2003; 52: 439-445.

9 Gilligan DM, Guetta V, Panza JA, Garcia CE, Quyyumi AA, Cannon III RO. Selective loss of microvascular endothelial function in human hypercholesterolemia. Circulation 1994; 90: 35-41.

10 Stokes KY, Clanton EC, Clements KP, Granger DN. Role of interferon-gamma in hypercholesterolemia-induced leukocyte-endothelial cell adhesion. Circulation 2003; 107: 2140-2145.

11 Rodriguez-Porcel M, Lerman A, Ritman EL, Wilson SH, Best PJ, Lerman LO. Altered myocardial microvascular 3D architecture in experimental hypercholesterolemia. Circulation 2000; 102: 2028-2030.

12 Bentley MD, Rodriguez-Porcel M, Lerman A, Sarafov MH, Romero JC, Pelaez LI et al. Enhanced renal cortical vascularization in experimental hypercholesterolemia. Kidney Int 2002; 61: 1056-1063.

13 Klein R, Sharrett AR, Klein BE, Chambless LE, Cooper LS, Hubbard LD et al. Are retinal arteriolar abnormalities related to atherosclerosis?: The Atherosclerosis Risk in Communities Study. Arterioscler Thromb Vasc Biol 2000; 20: 1644-1650.

14 Wong TY, Klein R, Sharrett AR, Manolio TA, Hubbard LD, Marino EK et al. The prevalence and risk factors of retinal microvascular abnormalities in older persons: The Cardiovascular Health Study. Ophthalmology 2003; 110: 658-666.
15 van Leiden HA, Dekker JM, Moll AC, Nijpels G, Heine RJ Bouter LM et al. Blood pressure, lipids, and obesity are associated with retinopathy: the Hoorn study. Diabetes Care 2002; 25: 1320-1325.

16 Hubbard LD, Brothers RJ, King WN, Clegg LX, Klein R, Cooper LS et al. Methods for evaluation of retinal microvascular abnormalities associated with hypertension/ sclerosis in the Atherosclerosis Risk in Communities Study. Ophthalmology 1999; 106: 2269-2280.

17 Sherry LM, Wang JJ, Rochtchina E, Wong T, Klein R, Hubbard L et al. Reliability of computer-assisted retinal vessel measurement in a population. Clin Exp Ophthalmol 2002; 30: 179-182.

18 Leung H, Wang JJ, Rochtchina E, Tan AG, Wong TY, Hubbard LD et al. Computer-assisted retinal vessel measurement in an older population: correlation between right and left eyes. Clin Exp Ophthalmol 2003; 31: 326-330.

19 Diabetic Retinopathy Study Research Group. DRS Report Number 7: a modification of the Airlie House classification of diabetic retinopathy. Invest Ophthalmol Vis Sci 1981; 21: 210-226.

20 Klein R, Davis MD, Magli YL, Segal P, Klein BE, Hubbard L. The Wisconsin age-related maculopathy grading system. Ophthalmology 1991; 98: 1128-1134.

21 Yu T, Mitchell P, Berry G, Li W, Wang JJ. Retinopathy in older persons without diabetes and its relationship to hypertension. Arch Ophthalmol 1998; 116: 83-89.

22 Wang JJ, Mitchell P, Leung H, Rochtchina E, Wong TY, Klein R. Hypertensive retinal vessel wall signs in a general older population: the Blue Mountains Eye Study. Hypertension 2003; 42: 534-541.

23 Wong TY, Hubbard LD, Klein R, Marino EK, Kronmal R, Sharrett AR et al. Retinal microvascular abnormalities and blood pressure in older people: the Cardiovascular Health Study. Br J Ophthalmol 2002; 86: 1007-1013.

24 Wong TY, Klein R, Couper DJ, Cooper LS, Shahar E, Hubbard LD et al. Retinal microvascular abnormalities and incident stroke: the Atherosclerosis Risk in Communities Study. Lancet 2001; 358: 1134-1140.

25 Wong TY, Klein R, Sharrett AR, Duncan BB, Couper DJ, Tielsch JM et al. Retinal arteriolar narrowing and risk of coronary heart disease in men and women. The Atherosclerosis Risk in Communities Study. JAMA 2002; 287: 1153-1159.

26 Wong TY, Klein R, Nieto FJ, Klein BE, Sharrett AR, Meuer $\mathrm{SM}$ et al. Retinal microvascular abnormalities and 10-year cardiovascular mortality: a population-based case-control study. Ophthalmology 2003; 110: 933-940.

27 Tomida K, Tamai K, Matsuda Y, Matsubara A, Ogura Y. Hypercholesterolemia induces leukocyte entrapment in the retinal microcirculation of rats. Curr Eye Res 2001; 23: 38-43.

28 Yamakawa K, Bhutto IA, Lu Z, Watanabe Y, Amemiya T. Retinal vascular changes in rats with inherited hypercholesterolemia - corrosion cast demonstration. Curr Eye Res 2001; 22: 258-265.

29 Dodson PM, Galton DJ, Winder AF. Retinal vascular abnormalities in the hyperlipidaemias. Trans Ophthalmol Soc UK 1981; 101: 17-21.

30 Dodson PM, Galton DJ, Hamilton AM, Blach RK. Retinal vein occlusion and the prevalence of lipoprotein abnormalities. Br J Ophthalmol 1982; 66: 161-164. 
31 Orlin C, Lee K, Jampol LM, Farber M. Retinal arteriolar changes in patients with hyperlipidemias. Retina 1988; 8 6-9.

32 Dodson PM, Kritzinger EE. Underlying medical conditions in young patients and ethnic differences in retinal vein occlusion. Trans Ophthalmol Soc UK 1985; 104: 114-119.

33 Sharrett AR, Hubbard LD, Cooper LS, Sorlie PD, Brothers RJ, Nieto FJ et al. Retinal arteriolar diameters and elevated blood pressure: the Atherosclerosis Risk in Communities Study. Am J Epidemiol 1999; 150: 263-270.

34 von Eckardstein A, Nofer JR, Assmann G. High density lipoproteins and arteriosclerosis. Role of cholesterol efflux and reverse cholesterol transport. Arterioscler Thromb Vasc Biol 2001; 21: 13-27.

35 Foody JM, Ferdinand FD, Pearce GL, Lytle BW, Cosgrove DM, Sprecher DL. HDL cholesterol level predicts survival in men after coronary artery bypass graft surgery: 20-year experience from The Cleveland Clinic Foundation. Circulation 2000; 102: III90-III94.

36 Kuvin JT, Patel AR, Sidhu M, Rand WM, Sliney KA, Pandian NG et al. Relation between high-density lipoprotein cholesterol and peripheral vasomotor function. Am J Cardiol 2003; 92: 275-279.

37 Kuvin JT, Ramet ME, Patel AR, Pandian NG, Mendelsohn ME, Karas RH. A novel mechanism for the beneficial vascular effects of high-density lipoprotein cholesterol: enhanced vasorelaxation and increased endothelial nitric oxide synthase expression. Am Heart J 2002; 144: 165-172.

38 Schoenhagen P, Ziada KM, Vince DG, Nissen SE, Tuzcu EM. Arterial remodeling and coronary artery disease: the concept of 'dilated' versus 'obstructive' coronary atherosclerosis. J Am Coll Cardiol 2001; 38: 297-306.

39 Schnell GB, Robertson A, Houston D, Malley L, Anderson TJ. Impaired brachial artery endothelial function is not predicted by elevated triglycerides. J Am Coll Cardiol 1999; 33: 2038-2043.

40 Chowienczyk PJ, Watts GF, Wierzbicki AS, Cockcroft JR, Brett SE, Ritter JM. Preserved endothelial function in patients with severe hypertriglyceridemia and low functional lipoprotein lipase activity. J Am Coll Cardiol 1997; 29: $964-968$

41 Lundman P, Eriksson M, Schenck-Gustafsson K, Karpe F, Tornvall P. Transient triglyceridemia decreases vascular reactivity in young, healthy men without risk factors for coronary heart disease. Circulation 1997; 96: 3266-3268.

42 Denke MA, Winker MA. Cholesterol and coronary heart disease in older adults. No easy answers. JAMA 1995; 274: 575-577.

43 Howard G, Manolio TA, Burke GL, Wolfson SK, O'Leary $\mathrm{DH}$. Does the association of risk factors and atherosclerosis change with age? An analysis of the combined ARIC and CHS cohorts. The Atherosclerosis Risk in Communities (ARIC) and Cardiovascular Health Study (CHS) investigators. Stroke 1997; 28: 1693-1701.

44 Weverling Rijnsburger AW, Blauw GJ, Lagaay AM, Knook DL, Meinders AE, Westendorp RG. Total cholesterol and risk of mortality in the oldest old. Lancet 1997; 350: 1119-1123.

45 Karpe F. Postprandial lipoprotein metabolism and atherosclerosis. J Int Med 1999; 246: 341-355. 